\title{
AN EMPIRICAL STUDY ON DESIGNING \& IMPLEMENTING OF GRIDDED MANAGEMENT MODEL FOR URBAN \& RURAL PUBLIC SERVICE
}

\author{
Dr. Muhammad Imran Hanif 1 \\ Institute of Banking and Finance, Bahauddin Zakariya University, Multan, Pakistan \\ Bai Xiuyin² \\ College of Humanities and Law, Chengdu University of Technology, Chengdu China
}

Dr. Asif Kamran 3

School of Management \& Economics, Institute of Business \& Technology, Karachi, Sindh, Pakistan.

Gu Yinhua 4

College of Humanities and Law, Chengdu University of Technology, Chengdu China

\begin{abstract}
Purpose: This paper constructs a Gridded Management Model drawing upon the theory of Gridded Management, for Public Service Provision in Urban and Rural Areas on the basis of an analysis of the plight of Traditional Model of Public Service Provision.

Methodology: Under the guidance of policies, we can build a Resource Integration Platform using modern information technology and leverage the powerful functions of the platform enabled by Complex Computing Methods and Matching Mechanisms to mobilize all resources to provide effective and refined Public Service to the Public with quick response the accountability

Finding: With the help of this Mechanism, we can improve Public Service without increasing the overall supply of Public Service Provision. Through the study of Gridded Management Mechanism of Public Service Provision, we can improve the status quo of the research on the supply of Public Service in China which offers real help to the development of Public Service. Practical Implication: There is an urgent need to Redesign the Model of Urban \& Rural Public Service Provision and exploit unused Resources in the Current Service Provision System, with the aim of promoting equalization of Public Service in both Urban and Rural areas. It delivers the same standard of Public Service for both Urban and Rural Areas through optimization of Resource Allocation without requiring more supply and fundamental change to the content of service.
\end{abstract}

Keywords : Public service; Equalization; Gridded Management

Jel Classification: D920, E220, F210

\footnotetext{
* The material presented by the author does not necessarily portray the viewpoint of the editors and the management of the Institute of Business \& Technology (IBT)

1. Dr. Muhammad Imran Hanif :

2. Bai Xiuyin

3. Dr. Asif Kamran : asifkamrankhan@gmail.com

4. Gu Yinhua

(C) IBTJBS is published by the Institute of Business and Technology (IBT).

Main Ibrahim Hydri Road, Korangi Creek, Karachi-75190, Pakistan.
} 


\section{INTRODUCTION \& BACKGROUND OF THE STUDY}

Public Service providing is the most essential functions of Government. As the total amount of public service increases, significant improvement standard has been made in provisioning Public Service in Urban and Rural Areas. However, there are still big gaps in Public Service Provision in Urban and Rural Areas in terms of Education, Health Care, Living Standards and Social Welfare, especially in Rural Areas. The disparity between Public Service Provision in Urban and Rural Areas are shockingly visible. According to Sheng (2013), the number of hospital beds per thousand persons in Urban Areas is 6.8, but only 3.1 that in Rural Areas. While comparing the education spending in Urban and Rural Areas, Wu (2012) highlighted that the ratio between education-costs on Junior high schools in Rural Areas had raised from $64.49 \%$ to $87.37 \%$ since 2004 , but the absolute discrepancy remains largely unchanged compare to that in Urban Junior high school. The contradiction between the large amount of overall financial investment and the lack of financial support for individual Public Service co-exists with the contradiction between relative surplus in Public Service Provision in Urban Areas and insufficient provide of Public Service in Rural Areas. It highlights the conceptual and structural flaws in the Traditional Model of Public Service Provision.

Gridded Management has been applied in a number of areas of Public Management in China, generating good results. Introducing Gridded Management into Public Service Provision can help in rectifying the uncoordinated allocation of Public Service Resources, making full use of the existing resources by aligning dispersed and personalized service demands with irregular way of Service Provision. In this way, a solution for improving the efficiency and effectiveness of Public Service can be found.

\section{OVERVIEW OF STUDY}

\subsection{Studies on Equalization of Public Service Provision in Urban and Rural Areas}

Efficiency provision of Public Service has long been the focus of attention for Western Scholars. A large number of Scholars like Hughes (1995) described the contents, boundary and categories of Public Service in detail for arousing the interest of the Public on the efficiency of Public Service Provision. A number of theories on Public Service were created to prove the possibility of innovating the Mechanism of Public Service Provision on Operational level. Boyne, Powell, and Ashworth (2001) pointed out the need to align the supply and demand of Public Service Provision. Pradhan (2000) put forward some basic methods for analyzing Public Service Provision. Varous researchers (Stephen 2002; Toshihiro 2004; Bruce and Thiess 2006) pointed out the need to adjust the compensation for Public Service in Countries consisting of Federal States. Robinson (2006) put forward an institutional framework for fair and efficient provision of Public Service.

Chinese Scholars also conducted in-depth analysis on the status of Public Service Provision in China, focusing on Macro level issues such as Restructuring and Financial 
reform etc. In the view of Yu (2004) the relationship between the government and market should be reshaped. Gao (2008) highlighted the importance of providing essential and guaranteed Public Service for Balanced Social Development. Chen (2010) declared innovation in Public Service Provision. Zhu (2012) studied some technologies draw from other sectors and practices. Zhang (2005) suggested that market and social mechanisms could be introduced to solve problems such as high cost, low efficiency and poor quality related to Public Service Provision. Wang (2003) studied the enhanced market regulation regarding Public Service Provision from the angle of resource allocation, regional disparity and public finance. Chi (2003) advocated a number of measures to equalize essential Public Services such as deepening reforms on financial system, establishing a sound public finance system as well as cross-region resource allocation.

Reviewing the results of all these researches, scholars have reached consensus on who should be the provider of Public Service Provision and what their responsibilities are and how important their efficiency. However, Scholars have evaded some key issues such as how to Provision Public Services and how proficiently the Services are Provisioned etc. Moreover, there is a lack of systematic and in-depth research on the issue of how to construct Mechanism of Public Service Provision with the help of New Technologies?

\subsection{Studies on Gridded Management}

Western scholars have carried out pioneering research on applying Grid Mechanism in Public Service Provision. Like other scholars Salamon (2012) believes that in order to improve the efficiency of Public Services funded by public money, it is necessary to carry out Gridded co-ordination between the Organizations providing funds and the Organizations delivering services. Wiener (2002) predicts that the Gridded InterOrganization Management will become a trend in the development of theories on Service-Oriented Organizations. Powell (2014) has discovered that Gridded Management can improve the operational efficiency of Non-Profit Organizations and Public Agencies. Milward (1998) believe that Co-operative Gridded Organization has become a prevalent mechanism for delivering Public Services. They have also suggested that the effectiveness of the Gridded co-operation should be measured. Mcguire (2012) even concluded that Gridded Management has become the central task of GOVERNANCE therefore must be put at the forefront of the Public Management research.

Gridded Management in China originated from exploration on how to improve Urban Management. Chen (2006) described the New Model for Gridded Urban Management in a systematic way. Meanwhile, the Gridded Management Promotion program is supported by a variety of State and Provincial Level programs such as 15th Five-year Key Science and Technology Programs and National Information Technology Demonstration Projects.

In summary, the Academic Community has reached a consensus on the feasibility of applying Gridded Management Mechanism in the Management of Public Services and the mechanism has proven to be effective in real-world application. However, relatively fewer studies have been conducted on how to optimize Public Service Provision by using Gridded Management Mechanisms and how to improve the efficiency of Public Service Provision using New Model and New Ideas. 


\subsection{Design of Gridded Management Model for Public Service Provision in Urban and Rural Areas}

The Gridded Management Mechanism for Public Service Provision we have constructed is a dynamic complex based on contract. With the help of this mechanism, we can improve Public Service without increasing the overall supply of Public Service Provision. While carrying out system design, by using Principles of Gridded Management and constructing a Gridded System structure for Public Service Provision is the first step of the journey. By using the Principles of Gridded Management, we constructed a fourlayer logical architecture at first. The four layers are: Public Service Resource formatting layer, Gridded Management access and application layer, Network Core middle ware layer and Public Service Grid Resource Allocation Management layer. Next, we divided each logical layer into multiple Physical Modules. According to the Characteristics of Public Service Provision, it aim is to ensure smooth operation of Public Service.

The Public Service Resource-Formatting Layer is divided into multiple physical modules (culture, health, sport, security) according to different types of Public Service. Based on the theory of Gridded Management, a unified information service platform is constructed to integrate different types of Public Service Resources dispersed in different departments and built a super virtual system of Public Service Provision in accordance with the Government Policies and Regulations. The purpose of the Network Core Middle Ware Layer is to enable automatic response and matching of public service resources. It involves applications of technologies and big data processing therefore is a key component for materializing the virtual allocation of Public Service Resources. The uppermost Public Service Grid Resource Orchestration Layer, is in essence a Public Service demand submission terminal which directly presents the picture of Public Service Resource supply and the demand for Public Services. From lowest to highest, the four-layer logic structure for Public Service Provision enables smooth transition from Specific Services to Automatic Provision. The two middle layers (i.e. Gridded Management Access Layer and Network Core Middle Ware Layer involve virtualization by technologists in accordance with the policies. The two outer layers (i.e. Public Service Resource Formatting Layer and Public Service Grid Orchestration Layer are directly operated by employees of Government Departments and the Ordinary People.

After the system is built, it is necessary to design the detailed processes of Gridded Management of Public Service Provision in Urban and Rural Areas so that it can operate smoothly. Dividing Public Services into a Multi-Layer Grid is a central part of Grid Resource Allocation. A scientific approach is needed in defining and dividing Grid Units. In this study, we explored the formation of the Gridded Management Model for Public Service Provision in Urban and Rural Areas on three levels:(a) Identifying "Points",(b) Defining "Square" and (c) Forming "Grid".

First, "Points" of Gridded Management for Public Service Provision are identified according to geographic location and service type. On one hand, we can employ geographic information coding technique to classify and encode the locations where Public Service is needed thus forming the basic location "Points" of Gridded Management. On the other hand, we can establish a Resourced Database according to the correlation between different types of Public Service thus forming information "Points" of Gridded Management. Both the "Location Points" and Information Points" are independent of 
each other without overlapping. A "Location Point" is the smallest location unit such as a household or street. "Information Point" is determined by a specific service demand. The Location Points are enriched by the social contents in the Resource Database, thus achieving fusion of location data and non-location data.

Second, "Squares" of the Gridded Management for Public Service Provision are created using a standardized template. The Public Service Grid concentrates a large variety of Public Service Resources, but the regional and content differences make it more challenging to define Squares. Generally, Defining "Squares" must follow the principle of "Reaching the Horizontal Boundary and Vertical Bottom". Considering the basic requirement of equalizing Public Service Provision in Urban and Rural Areas and standardizing similar Public Services at the same development stage creates a virtual "Square" of Public Service Resource. With centralized by allocation, institutional arrangement with multi-layer accountability and dynamic links in the Grid System, the past experience is linked to the current reality and the stock of supply is aligned with the demand. In this way, the Public Service Resources are fully shared and the virtual "Points" of Public Service Resources become "Squares" in real world. The co-ordination Mechanism would dynamically assign tasks to specific points, allocating Public Service Resources to locations in need.

Finally, the real "Points" and virtual "Squares" jointly form the "Grid" of Gridded Management for Public Service Provision in Urban and Rural Areas. After identifying the real "Points" and virtual "Squares" of Gridded Management for Public Service Provision, it is necessary to form the "Grid" through Resource Integration. To achievethis, we need to break the mental partition between different Departments, Bridge Management Hierarchies, integrate the dispersed Public Service Resources to produce "Equalization Effect, Convergence Effect and Systematic Effect" and, ultimately, improve the effectiveness of Public Service. After the "Grid" is formed, the Gridded Public Service Provision Mechanism will centrally allocate Public Service Resources following the principle of "Centralized Pooling, Multi-point Sharing", thus forming a Multi-dimensional, Dynamic and Responsive Public Management Model.

The Gridded Management Model for Public Service Provision is formed when identifying "Points", defining "Squares" and constructing "Grid". (seeing Figure 2) This Model can present the contents and locations of demands for Public Service clearly and timely, reveal the relationship between Public Services of different regions, periods and types and include Government Departments, Communities, Public, Enterprises and Public Institutions in a single framework.

Under the guidance of policies, we can build a Resource Integration Platform using modern information technology and leverage the powerful functions of the platform enabled by Complex Computing Methods and Matching Mechanisms to mobilize all resources to provide effective and refined Public Service to the Public with quick response the accountability.

\subsection{Implementation of Gridded Management Model for Public Service Provision in Urban and Rural Areas}

Gridded Management for Public Service Provision is a New Model for Public Service built on Electronic Grid Map and Mobile Information Technology. It aggregates service information on a "Point" platform, assigns service responsibilities in a "Square" domain 
and follow up the whole service process through dimension co-ordination of the "Grid". The operation of the model is powered the four Mechanisms - Triggering, Processing, Supervision and Feedback. (Figure 3).

First, we discuss about Triggering Mechanism. The Triggering Mechanism is triggered by submission of demand for Public Service. The demand can be submitted through various channels including network, face to face and hot-line. The Grid Supervisor is responsible for review the demand within a controllable scope. The Grid Supervisors verifies the authenticity and accuracy of the demand information and submit it to the Gridded Management System. After the Gridded Management System ascertains the availability and importance of the relevant Public Service, the application enters the Acceptance Stage. Next, the Gridded Management System allocates Public Service according to the existing Operation Mechanism. When an unsolvable problem is encountered, an expert consultancy node will be set up to provide professional analysis upon which a decision about whether to approve the service application. In order to improve the efficiency of Triggering Mechanism during the application Acceptance Stage, the service corresponding to the demand will be input into the Operation Mechanism of the Grid for processing.

Second, point is Processing Mechanism. After the demand information passes review, the application enters the Acceptance Stage during which information scrutiny and task analysis will be performed before the application is passed to the next section of the process. During this stage, the service applicant needs to provide contact details so that the handler can communicate with the applicant when necessary. Sometimes, additional documents may be needed. During the Processing process, the applicant can query the progress of the service, receive the service result and provide feedback. During the Demand Acceptance Process, various pieces of information (including demand information, classification of demand information etc.) are aggregated to form a demand information package. The package will be uploaded into the Gridded Management System process based on the classification of "Points" for splitting and dispatching. During the Task Division Stage, tasks are assigned to the functional Modules of relevant field of Public Service. (Figure 4).

Third is Supervision Mechanism. The supervision includes Resource Supervision and Work Supervision. The Resource Supervision involves timely updating of resource information for the purpose of improving the utilization of the dynamic Grid. In order to ensure that the resource control is closed loop, it is necessary to perform real-time monitoring on ongoing resource provisioning, data archiving and state presetting. The Work Supervision consists of two dimensions - Region Supervision and Layer Supervision. Horizontal (by region) and vertical (by layer) comparison will be made on the number of Public Service tasks and processing efficiency in regions of different levels. The Grid Platform monitors in real time the processing cycle and submits reports containing indicators on a regular basis. The assessment result will be produced regularly. The region with low efficiency in Public Service Provision will be asked to rectify problems. The assessment result will be used in the yearly performance assessment for the department. 
Fourth is Feedback Mechanism. Traditional assessment and Feedback Mechanism adopt the top-down approach. The Feedback Channels are very limited and "Managerial Island" is a common phenomenon. In a Gridded Management System, the Public Service Applicant would make an assessment on the processing process after receiving the service result. The service provider would make real-time adjustment in response to the feedback. The Feedback of the Service Applicant will be stored on the Grid Platform as an archived document. When a similar problems arises in the next cycle. A readily use-able solution can be found in the System and a New Operation Mechanism can be created based on the solution. The Feedback of the Service Applicant is an external feedback and an objective assessment criterion should be devised. A four-grade system (A - very satisfied, B - satisfied, C - just so so, D - unsatisfied) is designed for assessing the user satisfaction on service quality such as information releasing and quality of service result etc. The assessment will be carried out based on the recorded data on the Grid Platform and answers to a number of subjective questions. The Service Application will also be asked to give suggestions on how to improve the Gridded Management System.

The Gridded Management System employs network and information technologies and $3 \mathrm{~S}$ technologies (remote sensing, geographic information system and global positioning system) to enable dynamic and visualized presentation of Public Service Provision in Urban and Rural Areas. Two databases (Geographic Codes \& Service Content Database Pair) will be established to store various standardized information such as geographic codes of the existing Public Service Resources, Service Network, Resource Status and Contact Details. These two databases are composed of "Points" of Public Service, represented by user terminals for authentication and demand submission. When the dispersed demands converge at the "Points", the need for competent departments to define, dispatch, split and execute tasks is created. The competent departments take advantages of the "Squares" to standardize service processes, including application acceptance, task splitting, task execution and service delivery. This is a close-loop process that enables "unified information entry points, standardized process procedures and seamless connection of layers."

The Services are centrally managed on a Unified Platform where the information ingresses in Urban Areas are identical to those in Rural Areas. The entered information is absorbed into the system immediately, thus helping avoid resource waste due to time difference. The Gridded Sharing Platform enables "one to multiple" (i.e. one public service demand can be allocated with multiple service resources within the network framework) and "multiple to one" (i.e. multiple service demands share the same resource package at the same time) modes of demand-resource matching. This eliminates unnecessary labor during the process of Resource Allocation. The classification step serves to assign Public Service demands to the corresponding resource zones for data sharing and fund allocation and so on. After the orchestration of resource packages, an assessment on whether the problem in service resources allocation has been solved will be made during the case closing process. If the problem has not been solved effectively, the problem will be transferred to the Processing System. If the problem has been solved, the result will be feedback to the System for regular processing and System repair. Gridded Management of Public Service Provision facilitated engagement between Government Agencies and the Public. On one hand, transparent access to relevant 
information allows the Public to get informed of how the resources are being allocated at any time. On the other hand, Standardized Resource Allocation Mode allows' administrators to understand the situation on the ground such as the availability of Service Resources, thus eliminating the drawbacks of Traditional Model for Public Service Provision such as blocked information channel and difficulties in resource orchestration.

The Gridded Management for Public Service Provision has overcome the low efficiency of the Traditional Management Model by rich information of Sound Organizational Structure, Sophisticated Operation Mechanisms and Optimized Allocation Procedures. The Gridded Platform can allocate resources according to the Public Service Demands. In addition to improving the operational efficiency of Government Agencies and enabling rational Resource Allocation, the Gridded Platform can reduce the workload of direct communication for the Service Delivery Departments. As misunderstanding may occur due to reduced face-to-face communication, it is imperative for the Government Agencies to transform themselves in terms of mentality and attitude, from waiting passively for the Service Demands to identifying needs and providing service proactively. It is necessary to split the duty of Supervision and the duty of Management, establish a Supervision System within the Gridded Platform. The effectiveness of Public Service Provision should be assessed based on relevant data recorded during daily operation and the automatically generated assessment result will be used for performance assessment. Feedback from the Service Receivers on the quality of service should be used for assessing the effectiveness of Service Provision. By combining internal supervision on task execution with external supervision in the form of comment, a consummate Gridded Management Model for Public Service Provision will take shape, with information as its nexus, duty as its engine and service as its goal.

\section{CONCLUSION}

Urban-Rural inequality in Public Service Provision has become a key factor contributing to the overall inequality between Urban and Rural Areas. The necessity of exploring a new path towards equalization of Public Service Provision in Urban and Rural Areas has become a consensus of Government Agencies and Academic Community. The allencompassing, rapid response and high responsiveness nature of Gridded Management provides a new approach to achieving equalization of Public Service Provision. As a Management philosophy, Gridded Management Mechanism for Public Service Provision breaks the boundaries of departments and business unit using high-efficient Organization and Operation processes and aligns the dispersed and personalized Service Demands with irregular Service Supplies to best satisfy the Public's needs for Public Service.

By centralized allocating and coordinated sharing of Public Service Resources and bridging the Management Hierarchies, the Gridded Management Mechanism for Public Service Provision can stimulate the spontaneity of the Government Agencies supplying Public Services and help meet the Public's Demands for Public Service through rapid and distortion-free information circulation. Instead of requiring larger investment on Public Service, the New Management Mechanism helps increase the benefits of Public Service by adjusting the Mode of Public Service Provision and improve the utilization 
of existing resources.

The Gridded Management Mechanism of Public Service Provision is a dynamic complex based on contract. With the help of this Mechanism, we can improve Public Service without increasing the overall supply of Public Service Provision. Through the study of Gridded Management Mechanism of Public Service Provision, we can improve the status quo of the research on the supply of Public Service in China which offers real help to the development of Public Service. We need to put emphasis on the right to enjoy Public Service equally and get service according to needs, create conditions for improving efficiency and degree of equality and solve problems such as Urban-Rural Inequality in Public Service Provision.

\section{ACKNOWLEDGEMENT}

First of all with a profound gratitude, we are thankful to Almighty Allah forgiving us success, knowledge and understanding without which we would not been capable of completing this research paper.

We are also profoundly grateful to all our family members whose endurance and understanding have played a significant role in our success by sacrificing the important family time and supporting us all over the research work.

We are finally thankful to the editor, reviewers and IBT specially who provided us with the opportunity to publish our research paper in this esteemed journal.

\section{REFERENCES}

Chen P (2006). Gridded Management - A New Model for Urban Management(153). Beijing University Press.

Chen ZM (2010). Citizens' Attitudes Toward Local Government Public Service. Public Performance \& Management Review, 34(2):221-235.

Chi FL (2003). China's Reform Focuses on Streamlining Government. Transition Newsletter, 14 (1-3).

Cui CY (2008). Promoting our country public service marketization. Journal of Sichuan Administration College, (01):32-34.

Elinor O (2012). Reflections on Vincent Ostrom, Public Administration, and Polycentricity. Public Administration Review, 72(1):15-25.

George B (2001). Environment change, leadership succession and incrementalism in local government. Journal of Management Studies, 38(6):859-878. Jin RQ (2006). hina's rural mission. The Banker, 156(959):10. Jin YZ (2008). Study on Contemporary German Local Government Public Service Reform. Chinese Public Administration, (01):103-107.

Ju H (2010). Range of Applications of contracting out for public services: contrast between theory and practice. Chinese Public Administration, (04):51-55. K.Skylar P (2014). Profitability and Speed of Foreign Market Entry. Management International Review, 54(1): 31-45.

Kilkon K; Lulu H (2013). An Empirical Study on Public Service Motivation of the Next Generation Civil Servants in China. Public Personnel Management, 42(2):191-222. 
Liu MP (2007). Studying on the dynamic mechanism of China's non government organizations in rural areas of growth. Theory and Reform, (04):66-68. Mao SL (2006). Will the Latest Official Care Reform Plan Succeed?. Beijing Review, 49(3):46.

Michael M (2012). A Look Behind the Scenes. Public Administration Review, 72(2): 171-172.

Milward, H.Brinton; Provan, Keith G. (1998). Principles for controlling agents: The political economy of network structure. Journal of Public Administration Research and Theory, 8(2): 203-203.

Owen E.Hughes (1995). Pro-competitive regulation as a role of government. Australian Journal of Public Administration, 54(3):364-369.

Richard M. Clerkin; Jerrell D. Coggburn (2012). The Dimensions of Public Service. Motivation and Sector Work references. Review of Public Personnel Administration, 32(3):209-235.

Robert A (1999). Managing in network settings. Review of Policy Research, 16(1): $18-41$.

Salamon R (2012). The use of regional platforms for managing electronic health records for the production of regional public health indicators in France. BMC Med Inform Decis Mak, 12:28.

Sheng LY (2013). China Statistical Yearbook, (21-7) Numbers of Hospital Beds in Urban and Rural Health Care Institutions, China Statistics Press, (756). Ted G (1992). Reinventing Government. PM.Public Management, 74(3):4.

Tian; Li (2008). An interoperable Spatial Decision Support System based on geospatial semantic web technologies. Proceedings of SPIE-The International Society for Optical Engineering, (7144).

Tu XF (2002). Effects of the government interest on the government behavior. Chinese Public Administration, (10):16-18.

Wang W (2003). Simulation of Large-Scale Field Infiltration Experiments Using a Hierarchy of Models Based on Public, Generic and Site Data. Vadose Zone Journal, 2(3):297.

Wiener JM (2002). Health policy for low-income people:states"responses to new challenges. Health affairs. Suppl Web Exclusives :W187-W218. Wouter V (2014). Explaining Public Service Motivation: The Role of Leadership and Basic Needs Satisfaction. Review of Public Personnel Administration, 34(2):153173.

Wu GS (2012). China Statistical Yearbook of Education Funding - 2012, China Statistics Press, (04).

Yan Li (2014). Urban planning support systems in Japan: evolutions and implications. International Journal of Society Systems Science, 6(1):4-17.

Yang T (2004). Minimum income schemes for the unemployed: a case study from

Dalian, China. International Social Science Journal, 56(1):2. Zhang X (2005) .Coping with globalisation through a collaborative federate mode of governence: The Case of China in Transition. Policy Studies, 26(2):199. Zhili C, Zhihui D, Yinong Chen, Suihui Zhu, Man Wang (2009). Optimizing Service Data Transmission in An OGSA Based Grid System. Journal of Algorithms \& Computational Technology, (12).

Zhou ZR (2010). Performance Management in the Government of the People's Republic 
of China:Accountability and Control in the Implementation of Public Policy. OECD Journal on Budgeting, 10(2):1-28.

Zhu XN, Bai XY (2010). Study on Gridded Management Mechanism for Public Service under the Policy of Coordinated Urban and Rural Development, Chinese Public Administration, (09).

Zhu XN (2012). System Guarantee for Social Equity in Today's China. Cross-Cultural Communication, 8(5):50-54. 
(Figure 1)
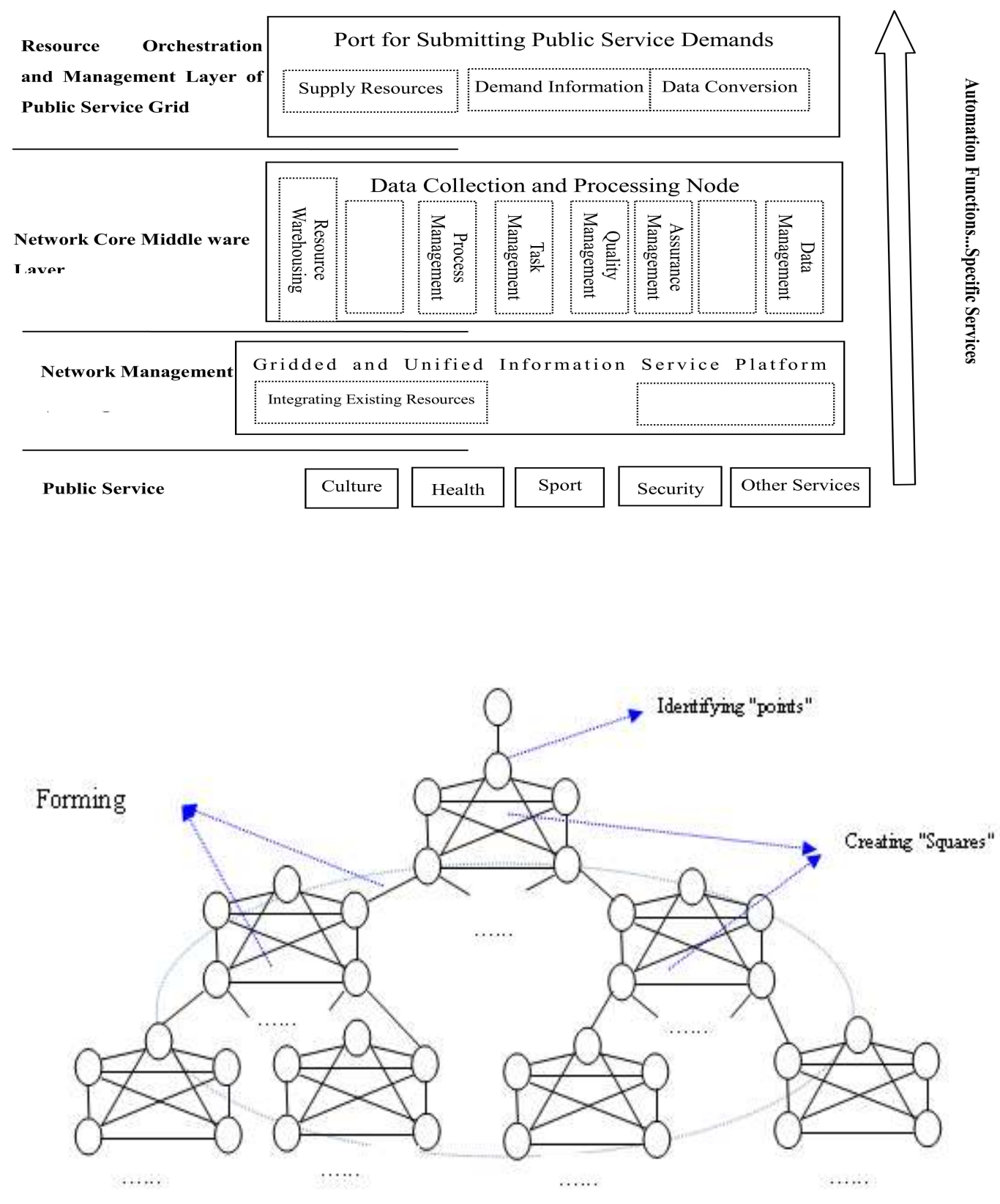
Figure 3: Implementation of Gridded Management Model for Public Service Provision

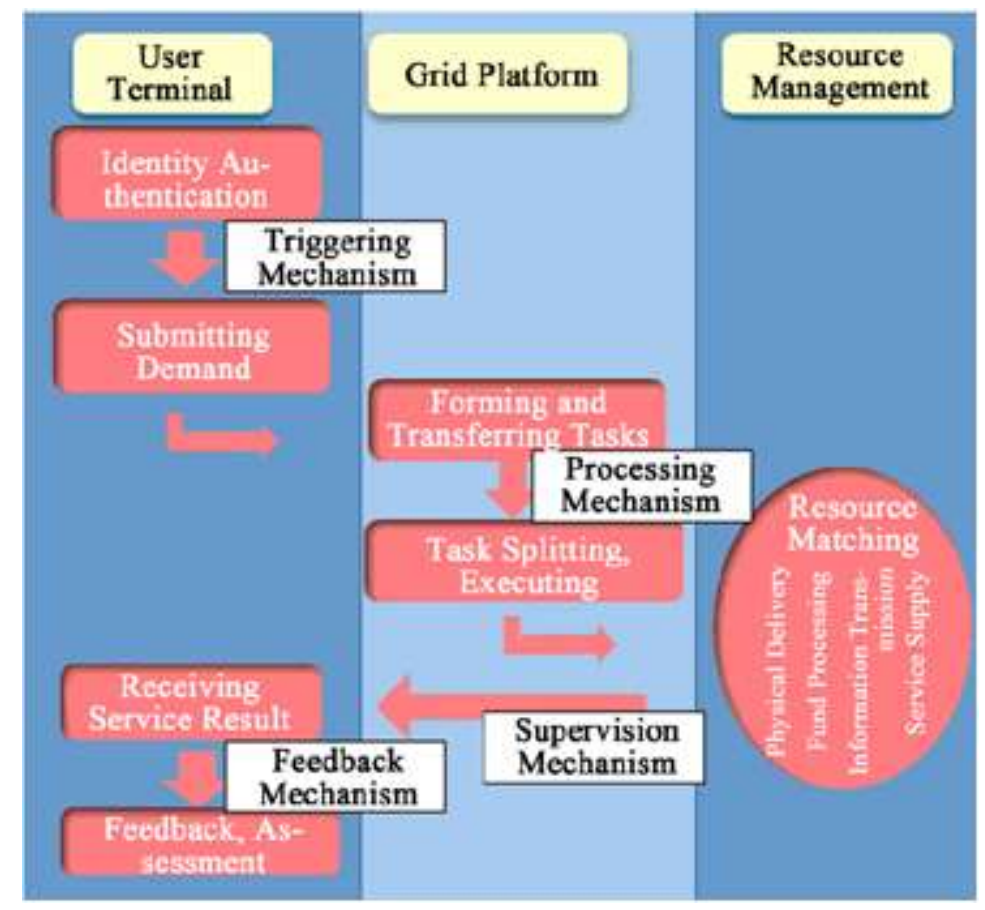

\section{Figure 4: Processing Mechanism of Gridded Management}

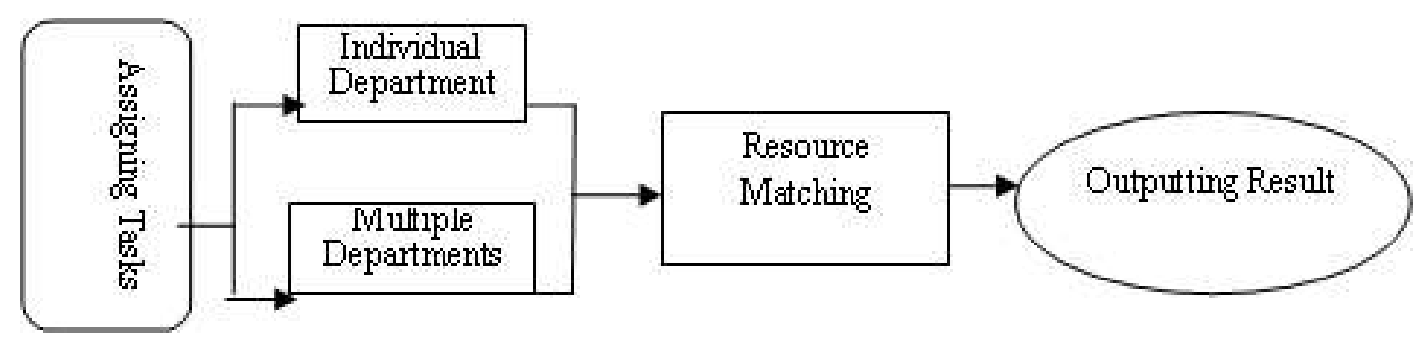

